Canadian Studies in Population, Vol. 37.1-2, Spring/Summer, pp. 277-279

\title{
Population and Disease: Transforming English Society, 1550-1850
}

\author{
Peter Razzell \\ Pittsburgh, PA: Caliban Books, 2007 \\ ISBN: 978-185066477 \\ $£ 45.00,337$ pages \\ Kevin McQuillan \\ Faculty of Social Sciences \\ University of Calgary \\ Email: kevinmcq@ucalgary.ca
}

Peter Razzell occupies a curious place in the history of English demography. He has been writing about the history of the English population for some forty years and has always taken up the position of critic of the established wisdom. His earliest work, dating to the nineteen sixties, has questioned the leading interpretations of England's demographic history. Razzell, now a professor at the University of Essex, launched his career with an attack on the very influential work of Thomas McKeown. McKeown had argued that declining mortality in the late eighteenth and nineteenth centuries led to a significant rise of England's population, and the decline in mortality was due, above all, to improved nutrition. Razzell was unconvinced. In a series of important articles, he challenged the McKeown position. Specifically, he rejected the view that medical developments played no significant role in mortality decline until a late date and pointed to the importance of a number of medical improvements including smallpox vaccination. In the 1990s, Razzell went on to attack another icon of English demography: the Cambridge Group for the History of Population and Social Structure. The work of Wrigley and Schofield was the "gold standard" of English population history, but Razzell was deeply critical of their work, believing that their methodological approach led them and their readers astray. Although a gadfly, Razzell has not been relegated to the sidelines of demographic research. His work has appeared in leading journals including Population Studies, The Economic History Review, and Journal of Economic History among others. 
The present volume brings together a number of his more recent papers. It is an odd collection. Six of the papers were previously published. One paper is an extended book review of the second major book by E.A. Wrigley and his associates and originally appeared in the Social History of Medicine. Another is the Introduction to the second edition of his book The Conquest of Smallpox. It is unlikely that any reader of this journal would sit down and read the book from cover to cover. Yet the book provides a service by bringing together a set of writings that reflect Razzell's unique contribution to historical demography.

I will not attempt to summarize or critique the ten papers in the volume. Razzell has chosen papers for inclusion which address three major issues that have concerned him throughout his career: methodology, the story of England's population growth from 1550-1850, and the decline of mortality. In addition, he adds two papers less tied to his major interests on the social and economic consequences of population change. Let me say a few words about what I see as the most significant papers in the volume.

A hallmark of Razzell's work is a deep suspicion of complex statistical approaches. Although the distinction between the approaches of historians and demographers who study population in the past is anything but clear, Razzell clearly feels more comfortable with an approach more connected to the historian. Demographic projections and model life tables are not the tools he chooses to work with. Instead he argues for a wide use of primary sources and a rigorous critique of the quality of available data. The first two papers in the volume are excellent illustrations of his careful attention to assessing the quality of available sources and demonstrate his preference for combining material from a wide variety of sources to shed light on the demography of the past.

It is from this perspective that he goes on to attack both the early work of the Cambridge Group that employed back projection techniques built on a series of assumptions that are open to debate, and the 1997 volume by members of the Group which employed the more traditional methods of family reconstitution. The present volume contains his lengthy critique of the second volume. I suspect most historical demographers will feel he goes overboard in his questioning of family reconstitution, a technique that brought historical demography to prominence, while accepting many of his specific criticisms of the application of the technique to rather shaky English data.

Razzell is perhaps best known for his work on historical mortality, including his critique of McKeown, noted above, but also his detailed history of the development of smallpox inoculation and vaccination. Readers of this volume will benefit most from his very useful summary of research on changing practices of personal and public hygiene and their likely effects on mortality. Strikingly, the often polemical tone that marks much of Razzell's work is missing here. Instead, we have a balanced summary of the current state of the problem that attributes positive consequences to a variety of developments including changes in clothing, breastfeeding, and piped water as well as the

CSP 2010, 37.1-2: 277-279 
improvements in the treatment of smallpox that he has emphasized in his own work.

This is not a book that many demographers, even historical demographers, will rush out to buy. But it is helpful to bring together this collection of papers by a man who has played a significant role in the development of historical demography in England. It will be a useful addition to the libraries of our universities where scholars now and in the future can go to consider the work of one of demography's leading iconoclasts. 